\title{
Multiple Scan Modes in the Hybrid Tandem Mass Spectrometric Screening and Characterization of the Glutathione Conjugate of 2-Furamide
}

\author{
Kevin D. Ballard, Mark J. Raftery, Hartmut Jaeschke, and Simon J. \\ Gaskell \\ Center for Experimental Therapeutics, Baylor College of Medicine, Houston, Texas, USA
}

\begin{abstract}
The glutathione conjugate of 2-furamide has been screened for and structurally characterized by tandem mass spectrometry (MS/MS) by using a hybrid instrument of BEqQ design. Mass spectrometry experiments employed fast atom bombardment (FAB) ionization of a crude bile extract from a rat dosed with a 1:1 mixture of unlabeled and $\left[{ }^{13} \mathrm{C}_{1}\right] 2$-furamide. Initial screening for glutathione conjugates employed constant neutral loss scanning to detect the loss of $129 \mathrm{u}$, corresponding to the loss of the $\gamma$-glutamyl moiety of the conjugates. By direct comparison with control bile, $[\mathrm{M}+\mathrm{H}]^{+}$ions of $m / z 417$ and 418 were readily identified as candidate ions corresponding to the glutathione conjugates of unlabeled and ${ }^{13} \mathrm{C}$-labeled 2 -furamide. Complementary screening information was generated by using a methylated bile extract, with constant neutral loss scanning to detect the loss of the methylated $\gamma$-glutamyl moiety $(143 \mathrm{u})$. An alternative screening procedure employing parent ion scanning to detect the sodium adducts of methylated glutathione conjugates was also developed. Structural information was generated by first-generation product ion scanning of the protonated and sodium cationized forms of the candidate species, both native and derivatized. This provided a body of internally consistent evidence that the conjugate retains the pseudoaromatic furan ring system without ring hydroxylation. The utility of sequential mass spectrometry (MS/MS/MS) capability of the hybrid instrument in the analysis of complex biological mixtures was also demonstrated. Using the bile extract, first-generation product ions that formed in either the first or second field-free region of the double-focusing portion of the instrument were subsequently collisionally activated in the rf-only quadrupole followed by mass analysis of the second-generation product ions. Structural information so provided for the glutathione conjugate of 2-furamide further substantiated its retention of the pseudoaromatic furan ring system and facilitated plausible assignment of structures to ionic species generated through multiple decomposition events. (J Am Soc Mass Spectrom 1991, 2, 55-68)
\end{abstract}

$\mathrm{N}$ umerous drugs and other xenobiotics have been demonstrated to undergo hepatic metabolic activation to highly reactive electrophilic intermediates that have the potential to react with hepatic macromolecules with toxic consequences. In many instances, conjugation of these intermediates with hepatic glutathione ( $\gamma$-glutamylcysteinylglycine), yielding the general structure I, represents an important detoxification pathway, such that when hepatic stores of glutathione are depleted the toxic properties of the xenobiotic become manifest; acetaminophen has become a classic example in exhibiting this mode of toxicity [1-4]. Because a knowledge of the structure of the glutathione conjugate(s)

Address reprint requests to Simon J. Gaskell, Center for Experimental Therapeutics, Baylor College of Medicine, I louston, TX 77030. of reactive intermediates yields insight into the toxic mechanisms involved, the identification and structural characterization of glutathione conjugates have become increasingly important, particularly with the continuing development of new drugs with the potential for drug-induced injury.

Xenobiotics that behave in the above manner are described as exhibiting a glutathione threshold of toxicity. Various substituted furans show differing behavior in this regard [5]; it is not clear whether this is associated with differences in metabolism, differing affinities for glutathione transferases, or other factors. As part of a broad study of these issues, the experiments described here involved the use of 2 -furamide, which exhibits a glutathione threshold of toxicity, as a model compound. The major objective of the present study was to identify and structurally characterize the 
<smiles>[R]SCC(NC(=O)CCC(N)C(=O)O)C(=O)NCC(=O)O</smiles>

Structure I

glutathione conjugate(s) of this compound formed in vivo.

Numerous mass spectrometric approaches to the characterization of glutathione conjugates have been assessed previously, including electron ionization (EI) [6], chemical ionization (CI) [7], desorption chemical ionization (DCI) $[8,9]$, field desorption (FD) [10-14], fast atom bombardment (FAB) and liquid secondary ion mass spectrometry (LSIMS) [15-34], and liquid chromatugraphy-thermospray mass spectrometry [35-41]. In general, more success has been achieved using the softer ionization techniques (FD, FAB, LSDMS, and thermospray) that generate abundant [M $+\mathrm{H}^{+}$ions, which may then be subjected to collision-activated decomposition (CAD) conditions. The resulting structurally informative fragment ions may be analyzed by various tandem mass spectrometric (MS/MS) approaches.

A general analytical strategy for the FAB/MS/MS identification and characterization of xenobiotic-derived glutathione conjugates has previously been reported from this laboratory [30]. This strategy involved high-performance liquid chromatographic (HPI.C) isolation of appropriate fractions of extracts of biological material, followed by constant neutral loss scanning as a compound class selective screening procedure to facilitate the detection of putative glutathione conjugates. For the constant neutral loss scans, a hybrid tandem mass spectrometer was set to monitor the loss of $129 \mathrm{u}$, corresponding to the loss of the $\gamma$-glutamyl moiety from the glutathione backbone of the conjugates. Precursor ions so identified by the screening procedure were then analyzed by product ion scanning to generate structural information. The well-characterized glutathione conjugate of acetaminophen was employed as a model compound for those studies. Other investigators subsequently employed a similar MS/MS approach to screen for and characterize glutathione conjugates of several xenobiotics as $\mathrm{N}$-benzyloxycarbonyl-bismethyl ester derivatives, which possess desirable chromatographic properties for HPLC isolation [29, 31, 32]. These derivatives also exhibit a characteristic loss of glycine methyl ester ( $89 \mathrm{u}$ ) as a neutral species, such that constant neutral loss scanning was again useful as a screening strategy [42].
During the present investigation of the metabolism of 2-furamide, the capabilities of hybrid MS/MS were used to greater advantage than previously, to permit the analysis of crude extracts of biological material without the need for elaborate purification schemes. Three alternative screening strategies involving simple derivatization were developed to provide information complementary to that of the original approach [30]. The variety of scan modes accessible on the hybrid instrument has been more extensively exploited, including two alternative approaches to sequential mass spectrometry (MS/MS/MS) that provide highly specific structural information from crude biological material.

\section{Experimental}

\section{Materials}

Unlabeled 2-furamide was obtained from Eastman Kodak Co. (Rochester, NY). All solvents were of HPLC grade and were used without further purification. Acetyl chloride (J.T. Baker Chemical Co., Phillipsburg, NJ) and heptafluorobutyric acid (Peninsular Chemresearch, Inc., Plainview, NY) were redistilled under argon prior to use. $\left[{ }^{2} \mathrm{H}_{4}\right]$ Methanol (isotopic purity 99\%) was purchased from MSD Isotopes (Montreal, Canada). All glassware used in these experiments was surface-deactivated by treatment with dichlorodimethylsilane/toluene $(4 / 96 \mathrm{v} / \mathrm{v})$ for $20 \mathrm{~min}$ followed by an absolute methanol rinse.

\section{Synthesis of $\left.l^{13} C_{1}\right] 2$-Furamide}

2-Furyllithium was produced by the method of Ramanathan and Levine [43]. Dry $\left[{ }^{13} \mathrm{C}\right]$ carbon dioxide [produced by dropwise addition of dilute hydrochloric acid onto $\mathrm{Ba}^{13} \mathrm{CO}_{3}$ (isotopic purity $>98 \%$; Aldrich, Milwaukee, WI) and dried by passage through anhydrous $\mathrm{CaSO}_{4}$ ] was bubbled through the 2-furyllithium to produce $\left[{ }^{13} \mathrm{C}\right] 2$-furoic acid, with the label in the carbonyl position. This product was then converted to the acid chloride [44] and amidated by using reported procedures [45].

\section{Animal Experiments}

Male Fischer rats $(230-320 \mathrm{~g})$ were anesthetized with sodium pentobarbital, and a laparotomy was performed followed by bile duct cannulation with PE-10 tubing. Control bile was collected from each animal for $30 \mathrm{~min}$. 2-Furamide, either pure unlabeled or a 1:1 mixture of unlabeled and ${ }^{13} \mathrm{C}$-labeled, was administered intraperitoneally in $1.5 \mathrm{~mL}$ of saline at a total dose of $200 \mathrm{mg} / \mathrm{kg}$. Bile was collected into preweighed glass vials over $15-30-\mathrm{min}$ intervals for a 2 -h time period. The collected samples were then weighed and stored at $-20^{\circ} \mathrm{C}$. 


\section{Ion-Pairing Extraction of Bile}

Bile samples were rendered $1 \%$ by volume in heptafluorobutyric acid (HFBA) [46, 47]. Reverse-phase $\left(\mathrm{C}_{18}\right)$ Sep-Paks (Waters Associates, Milford, MA) were charged with acetonitrile and washed with $10 \mathrm{~mL}$ of $0.1 \%$ aqueous HFBA. The samples were loaded, washed with $10 \mathrm{~mL}$ of $0.1 \%$ aqueous HFBA, and then eluted with $4 \mathrm{~mL}$ of acetonitrile/water $(4 / 1)$ containing $0.1 \%$ HFBA. The extracts were evaporated under nitrogen to remove excess acetonitrile, lyophilized, and redissolved in $200 \mu \mathrm{L}$ of acetonitrile/water (4/1) containing $0.1 \% \mathrm{HFBA}$. Aliquots $(1-2 \mu \mathrm{L})$ of the final solutions were used for MS/MS analysis.

\section{Derivatization Reactions}

Aliquots (25\% of the total) of the crude bile extracts were evaporated to dryness under nitrogen and methylated using freshly generated methanolic $\mathrm{HCl}$. Acetyl chloride $(440 \mu \mathrm{L})$ was slowly added to $1.56 \mathrm{~mL}$ of methanol at $0{ }^{\circ} \mathrm{C}$ under nitrogen, and this mixture was allowed to stand at $0{ }^{\circ} \mathrm{C}$ for $30 \mathrm{~min}$. Approximately $0.5 \mathrm{~mL}$ of this reagent was added to each dry bile extract, and the mixtures were allowed to stand at room temperature for $1 \mathrm{~h}$. The samples were then taken to dryness under nitrogen, followed by repeated additions of several drops of methanol and reevaporation to ensure removal of excess $\mathrm{HCl}$. The dry samples were redissolved in $50 \mu \mathrm{L}$ of methanol.

Methylation/deuteromethylation of crude bile extracts was performed identically except that the methylating reagent was prepared by using $290 \mu \mathrm{L}$ of acetyl chloride and $1 \mathrm{~mL}$ of a 1:1 mixture of unlabeled methanol and $\left[{ }^{2} \mathrm{H}_{4}\right]$ methanol.

\section{Mass Spectrometry}

Tandem mass spectrometric analyses were performed with a VG ZAB-SEQ (VG Analytical Ltd., Manchester, UK), a hybrid mass spectrometer of $B E q Q$ design ( $\mathrm{B}=$ magnetic sector, $\mathrm{E}=$ electric sector, $\mathrm{q}=\mathrm{rf}$ only quadrupole, and $Q=$ quadrupole mass filter). Fast atom bombardment ionization was employed with xenon for the primary atom beam, with the $\mathrm{FAB}$ gun operated at an encrgy of $8 \mathrm{keV}$. The $F \Lambda B$ matrix was a 1:1 mixture of 2,2-dithiodiethanol and thioglycerol, saturated with oxalic acid. The double-focusing portion of the hybrid instrument was typically operated at a resolution of $1200-1500$, with the quadrupole mass filter typically operated at 1-1.5 u resolution. All scan data were acquired in the multichannel analyzer (MCA) mode of the VG 11/250J data system to facilitate evaluation of the quality of the raw data, with six to eight scans typically accumulated. In some instances, these data were subsequently converted to a histogram format via the data system. It should be noted that the apparent resolution of full-scan plots of MCA data may appear artifactually degraded because of the compression algorithms incorporated in the plotting routines of the data system.

Conventional FAB spectra were recorded by using the double-focusing portion of the hybrid instrument. First-generation product ion spectra were obtained by manual selection of the precursor ion with the double-focusing portion of the instrument, with subsequent scanning of the quadrupole mass filter to detect the first-generation product ions formed in the rf-only quadrupole. Collision-activated decomposition conditions were employed for these experiments with argon as the target gas at a pressure of $1 \times 10^{-6} \mathrm{mbar}$ in the analyzer housing, corresponding to an estimated pressure in the collision region of $1.8 \times 10^{-4}$ mbar; the collision energy ranged from 6 to $70 \mathrm{eV}$ in the laboratory frame of reference. Constant neutral loss scans were obtained by simultaneously scanning the magnet and the quadrupole mass filter under the control of the data system with a constant mass offset of either 129,143 , or $146 u$ and a collision energy of 8 $\mathrm{eV}$. For precursor ion scans the quadrupole mass filter was set to transmit the product ion of interest $(\mathrm{m} / \mathrm{z}$ 324 in these experiments), and the magnet was scanned over a broad range to sequentially introduce the source-formed precursor ions into the rf-only quadrupole; CAD conditions for these experiments were again $1.8 \times 10^{-4}$ mbar argon in the rf-only quadrupole, with a collision energy of $22 \mathrm{eV}$.

Second-generation product ion spectra (MS/MS/ MS) were obtained in two ways. The first approach involved manual selection of first-generation product ions formed in the second field-free region of the mass spectrometer (FFR2) under metastable conditions. (For the MS/MS/MS analyses reported here, no significant improvement in signal intensity was achieved by incorporation of collision gas in FFR2.) The magnetic field strength was adjusted to select the precursor ion, followed by adjustment of the electric sector to select the first-generation product ion (effective mass resolution 300) using a previously described instrument modification that permits independent control of the electric sector field strength [48]. Firstgeneration product ions so selected were subjected to collisional activation in the rf-only quadrupole $(1.5 \times$ $10^{-4}$ mbar argon, $70 \mathrm{eV}$ collision energy), with subsequent mass analysis of the second-generation product ions with the quadrupole mass filter; $10-15$ scans were accumulated by the data system in MCA mode.

For the second approach to MS/MS/MS, appropriate settings of the magnetic and electric sector field strengths were established to select first-generation product ions formed in the first freld-free region (FFR 1) of the mass spectrometer. These settings were first adjusted to transmit product ions formed in FFR2 in the manner described above to permit optimization of the electric sector setting. The magnetic feld strength was then readjusted to a nominal value of $m_{\mathrm{f}}^{2} / \mathrm{m}_{\mathrm{p}}$, where $m_{\mathrm{f}}$ is the mass of the first-generation product ion and $m_{\mathrm{p}}$ is the mass of the precursor ion. The 
Figure 1. (a) Conventional FAB mass spectrum of a crude bile extract from a rat dosed with a 1:1 mixture of unlabeled and $\left[{ }^{13} \mathrm{C}_{1}\right] 2$-furamide. (b) constant nettral loss spectrum (monitoring the loss of $129 u$ ) of the same bile sample as in (a). (c) Constant neukal loss spectrum (129 u) of control bile extract from the same animal as in (a) and (b) prior to administration of 2-furamide. Signals in the constant neutral loss spectra are labeled as the $m / 2$ ratios of the precursor ions.
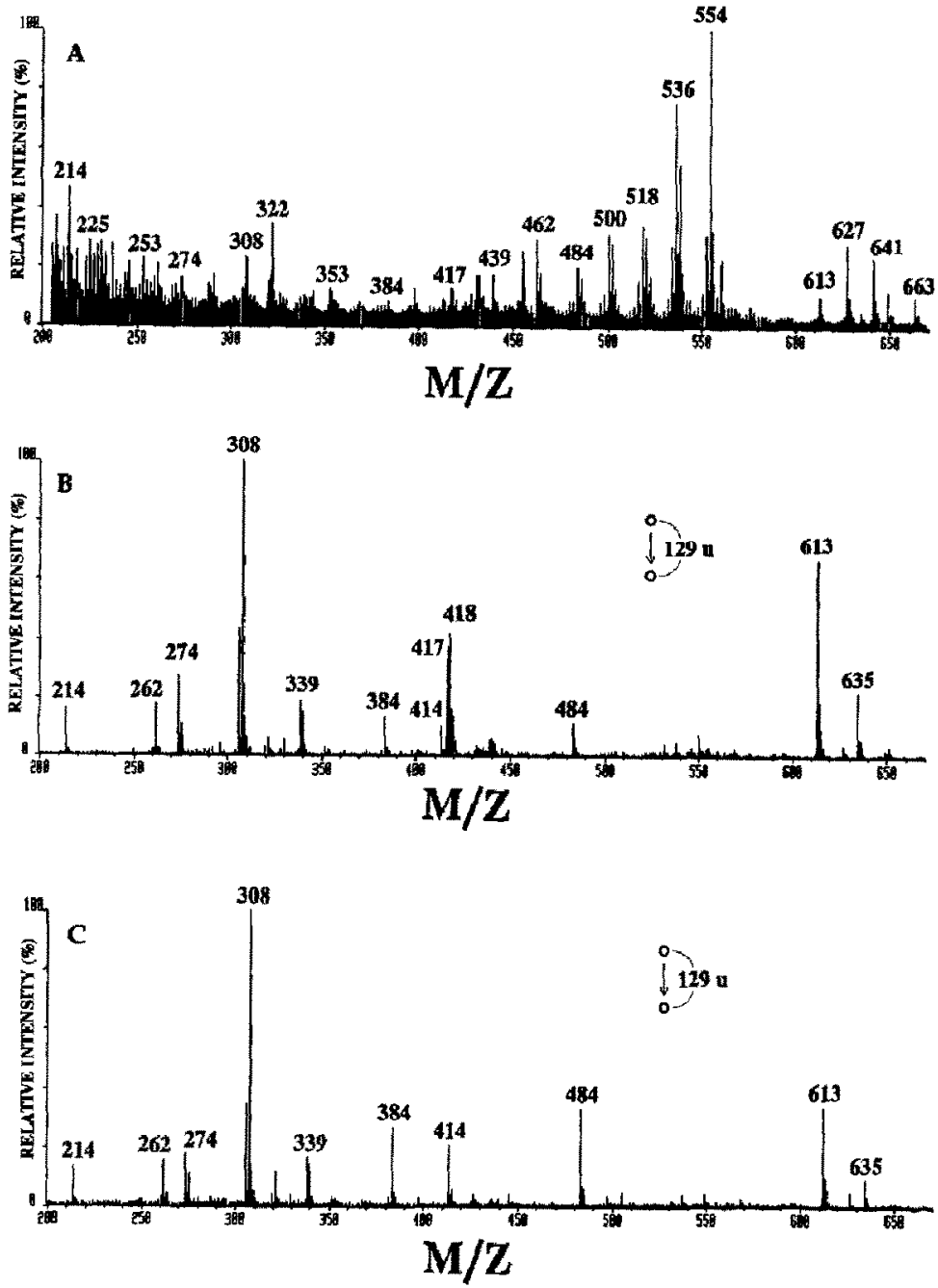

instrumental settings were thus appropriate for transmitting into the rf-only quadrupole collision region first-generation product ions of mass $m_{\mathrm{f}}$ formed from precursor ions of mass $m_{\mathrm{p}}$ in FFR1. First-generation product ions were then collisionally activated as described above, and the second-generation product ions so formed were again mass-analyzed as described above.

\section{Results}

The analytical strategy used in these studies involved extraction of the biological material, followed by compound class selective screening by hybrid MS/MS, with subsequent structural analysis of compounds identifed as pertinent by the screening procedures. Thus, initial studies focused on detecting the presence of 2-furamide-derived glutathione conjugates in crude bile extracts from rats dosed with the model com- pound. To facilitate these studies, the isotope cluster, or "twin ion," technique [49] was employed using a 1:1 mixture of unlabeled and ${ }^{13} \mathrm{C}$-labeled 2-furamide, with the stable-isotope-labeled material incorporating a single ${ }^{13} \mathrm{C}$ atom located in the carbonyl group. Whereas stable-isotope-labeled compounds differing from their urlabeled analogues by $1 \mathrm{u}$ generally do not serve well as intemal standards for quantitative purposes [50], for qualitative mass spectrometric applications a 1:1 doublet separated by $1 \mathrm{u}$ is the simplest pattern for pattern recognition. This approach is particularly valuable for the recognition of metabolites in complex biological extracts. Even with the twin ion technique employed, however, $\left[\mathrm{M}+\mathrm{H}^{+}\right.$ions attributable to xenobiotic-derived material are not always obvious in the conventional FAB spectra of complex mixtures. This is exemplified in Figure 1a, which presents the conventional FAB spectrum of a crude bile extract from a rat dosed with the 1:1 mix- 

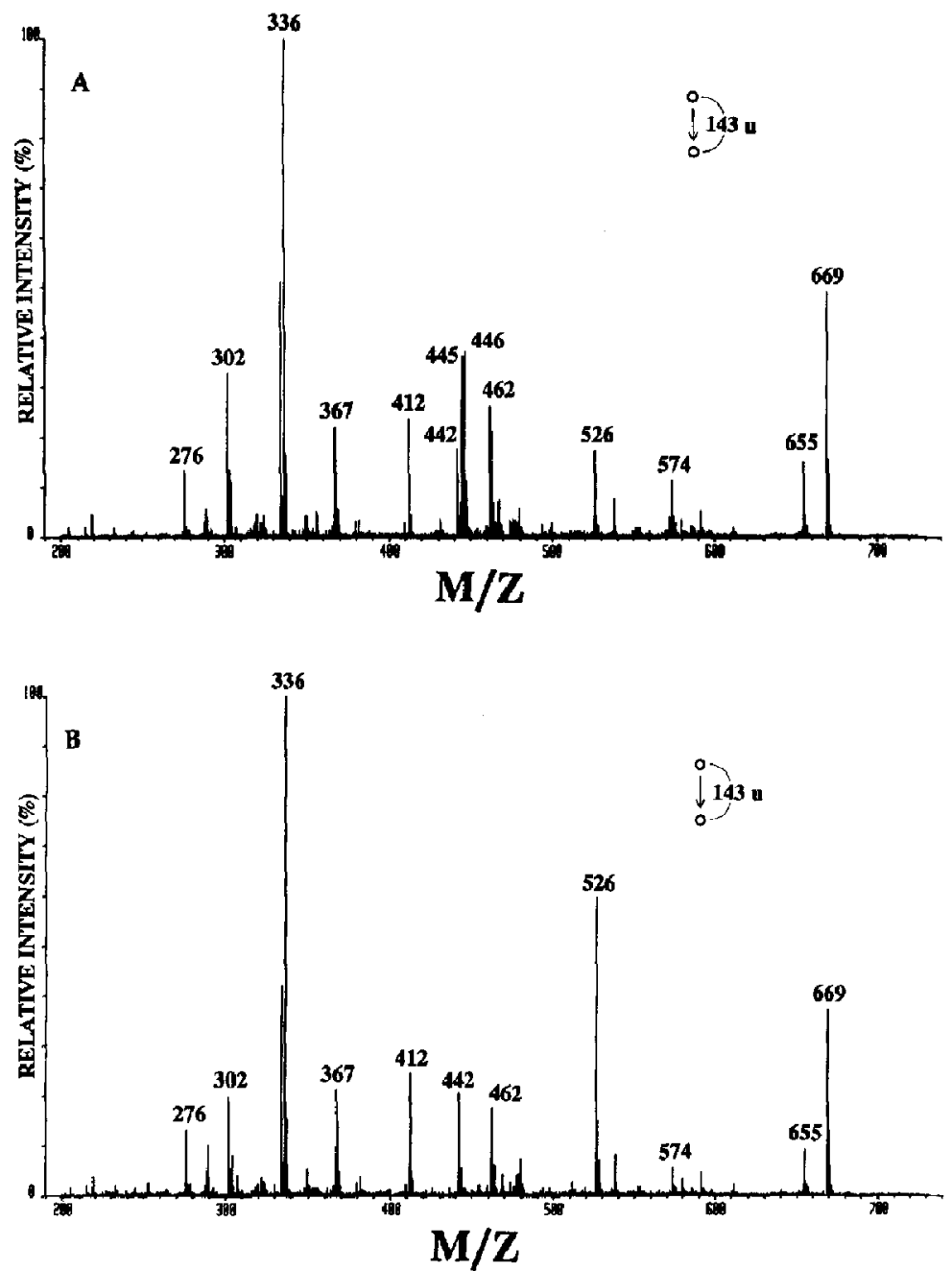

Figure 2. Constant neutral loss spectra (monitoring the loss of $143 \mathrm{u}$ ) of (a) xenobiotic-treated and (b) control bile extracts after methylation with methanolic $\mathrm{HCl}$. ture of unlabeled and ${ }^{13} \mathrm{C}$-labeled 2-furamide. Ions $\left([\mathrm{M}+\mathrm{H}]^{+}\right)$corresponding to glutathione in its reduced (monomeric) and oxidized (dimeric) forms ( $\mathrm{m} / \mathrm{z}$ 308 and 613, respectively) were readily assigned on the basis of a knowledge of the sample origin, but the obvious complexity and high background precluded the facile assignment of xenobiotic-derived $1: 1$ doublets. This complexity contrasts with the data of Figure $1 \mathrm{~b}$, in which is presented an MS/MS analysis of the same crude bile extract, with the hybrid instrument operated in the constant neutral loss scanning mode, monitoring the loss of $129 \mathrm{u}$, corresponding to the loss of a $\gamma$-glutamyl moiety from the glutathione conjugates [30]. (In this and other figures that present MS/MS data, the symbolism introduced by Cooks and co-workers is used to designate the scan mode [51].) Reduced glutathione formed the base peak in this spectrum, and the overall background was greatly reduced owing to the lack of detection of interfering species in this more specific scanning mode. Appar- ent $1: 1$ doublets were readily identified from this spectrum at $m / z 339 / 340$ and $417 / 418$, and when this spectrum was compared to an identical analysis of control bile from the same animal (Figure 1c), the doublet at $m / z 417 / 418$ was identified as distinct in the xenobiotic-treated versus control condition, with the $m / z 339 / 340$ doublet in both spectra. The use of constant neutral loss scanning in conjunction with the twin ion technique as a screening procedure thus permitted the assignment of $m / z 417$ and 418 as candidate $[\mathrm{M}+\mathrm{H}]^{+}$ions corresponding to glutathione conjugates of the unlabeled and ${ }^{13} \mathrm{C}$-labeled isotopic variants of 2 -furamide. In the constant neutral loss scanning mode, the signal-to-background ratio for these ionic species was approximately 25:1, as opposed to a corresponding ratio of $2: 1$ in the conventional FAB spectrum.

Further evidence toward the identification of these species as glutathione conjugates was generated by using the same crude bile extracts after methylation 


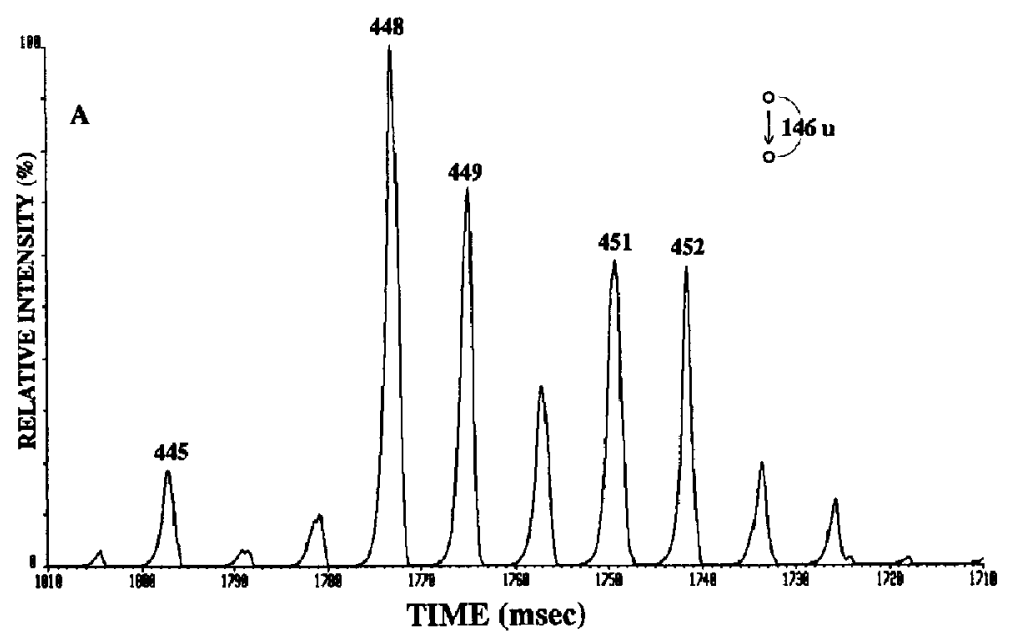

Figure 3. Expanded portions of constant neutral loss spectra (monitoring the loss of $146 \mathrm{u}$ ) of (a) xenobiotic-treated and (b) control bile extracts after methylation with $3 \mathrm{M} \mathrm{HCl}$ in a $1: 1$ mixture of unlabeled methanol and $\left[{ }^{2} \mathrm{II}_{4}\right]$ melhanol.

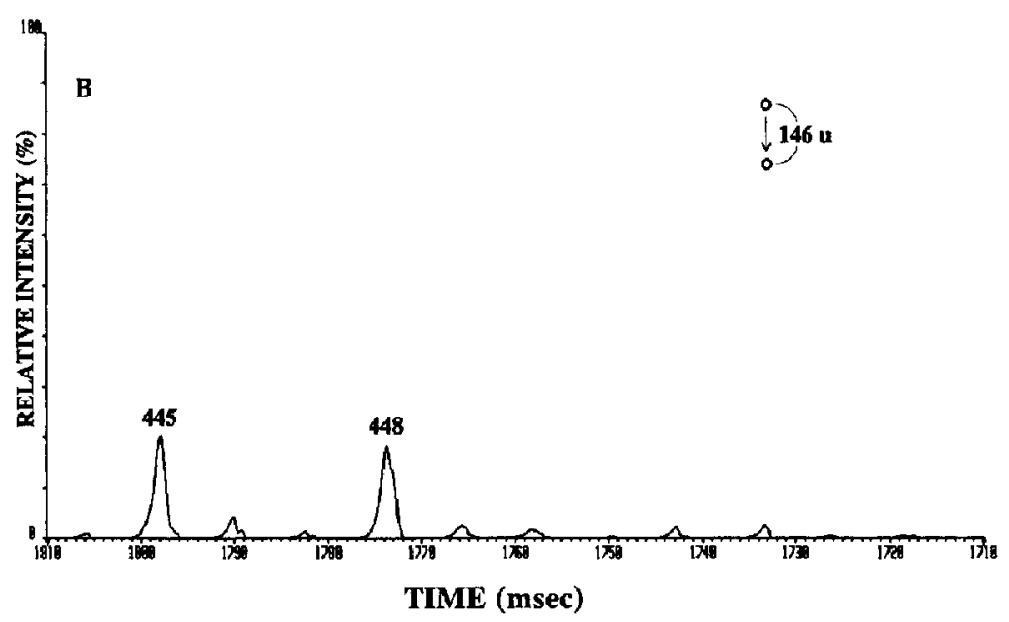

with methanolic $\mathrm{HCl}$. Constant neutral loss spectra of the methylated xenobiotic-treated and control extracts are presented in Figures $2 a$ and $2 b$, respectively; in this case the instrument was set to monitor the loss of $143 \mathrm{u}$, corresponding to the loss of the $\gamma$-glutamyl moiety as the methyl ester. These spectra were qualitatively similar to the corresponding spectra of the unmethylated material (Figures $1 b$ and $1 c$ ), except that the masses of the major peaks were shifted by multiples of $14 \mathrm{u}$, indicating the number of methylatable functions, presumably carboxylic acid groups, present in the native material. Reduced glutathione was shifted from $m / z 308$ to $m / z \quad 336$, consistent with the presence of two carboxylic acid groups; similarly, oxidized glutathione was shifted from $\mathrm{m} / \mathrm{z} 613$ to $m / z 669$, consistent with the presence of four functions amenable to methylation. The $1: 1$ doublet at $m / z 417 / 418$ was shifted to $m / z 445 / 446$, which is consistent with two carboxylic acid groups and thus further indicates the candidacy of these species as glutathione conjugates.

Simple methylation followed by constant neutral loss scanning employing a mass offset of $143 \mathrm{u}$ can thus form the basis of an alternative screening strategy for the detection of glutathione conjugates. This procedure was extended to include methylation with $3 \mathrm{M} \mathrm{HCl}$ in a $1: 1$ mixture of unlabeled methanol and $\left[{ }^{2} \mathrm{H}_{4}\right]$ methanol. Dicarboxylic acids so methylated generate an $[\mathrm{M}+\mathrm{H}]^{+}$ion isotopic pattern consisting of a triplet of ions separated by $3 \mathrm{u}$, with relative intensity ratios of $1: 2: 1$, corresponding to the $\left[{ }^{1} \mathrm{H}_{6},{ }^{2} \mathrm{H}_{0}\right],\left[{ }^{1} \mathrm{H}_{3}\right.$, $\left.{ }^{2} \mathrm{H}_{3}\right]$, and $\left[{ }^{1} \mathrm{H}_{0},{ }^{2} \mathrm{H}_{6}\right]$ forms of the derivative. For a glutathione conjugate, a scan for the loss of a neutral species of $143 \mathrm{u}$ would detect the $\left[{ }^{1} \mathrm{H}_{6},{ }^{2} \mathrm{H}_{0}\right]$ and $\left[{ }^{1} \mathrm{H}_{3},{ }^{2} \mathrm{H}_{3}\right]$ forms of the derivative as a 1:1 doublet separated by $3 \mathrm{u}$. Similarly, a scan for the loss of a neutral species of $146 \mathrm{u}$ would detect the $\left[{ }^{1} \mathrm{H}_{3},{ }^{2} \mathrm{H}_{3}\right]$ and $\left[{ }^{1} \mathrm{H}_{0},{ }^{2} \mathrm{H}_{6}\right]$ forms, again as a 1:1 doublet sepa- 

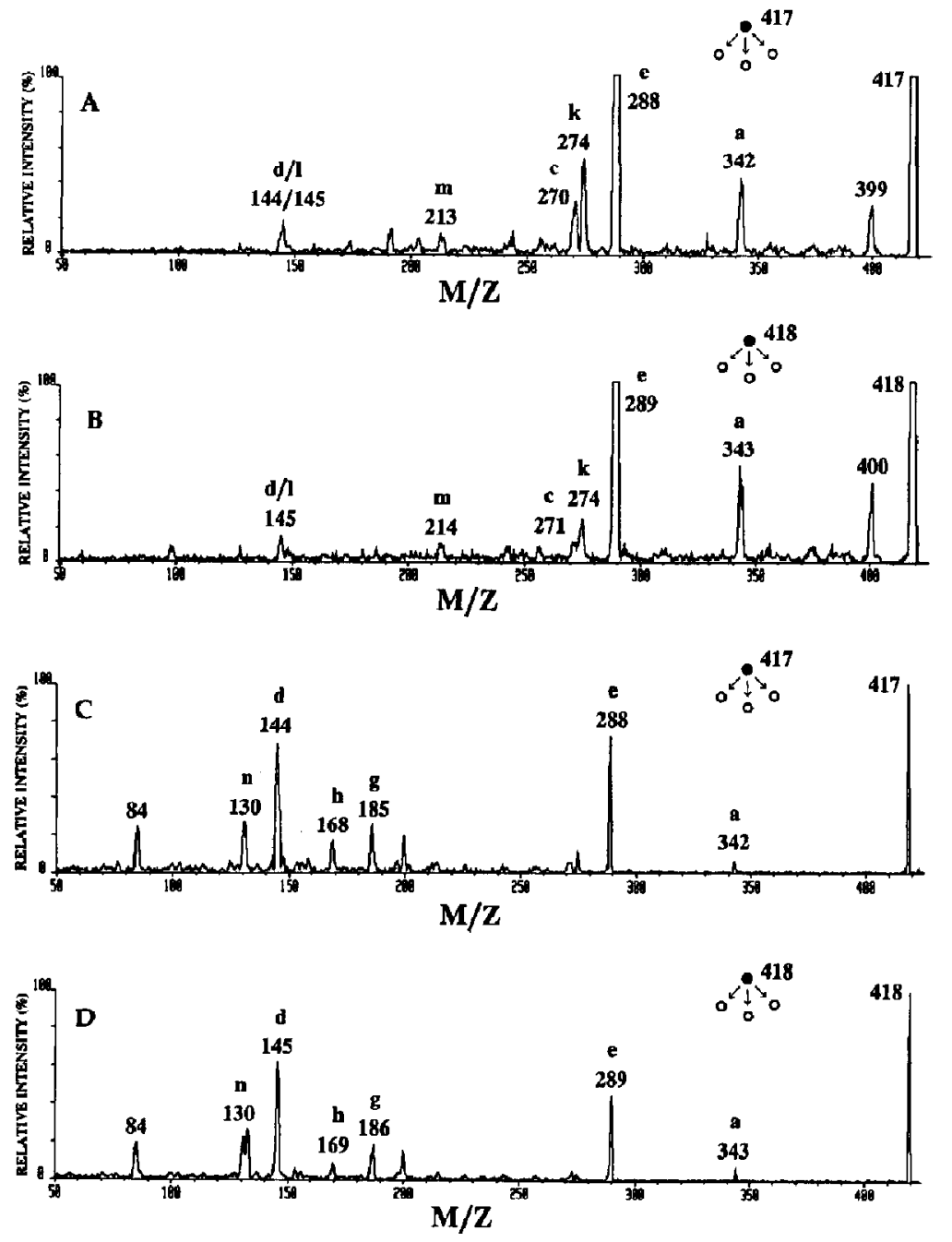

Figure 4. Low-energy CAD first-generation product ion spectra of the $\mathrm{m} / \mathrm{z}$ 417 (a and c) and $m / z \quad 418$ (b and d) species from xenobiotic-treated bile extract. The spectra in (a) and (b) were acquired under $6 . \mathrm{eV}$ CAD conditions; those in (c) and (d) were acquired under 70-eV CAD conditions. rated by $3 \mathrm{u}$. With the twin ion technique employed in conjunction with this procedure, xenobiotic-derived conjugates should appear as a quartet (two overlapping doublets) in the constant neutral loss spectra with a mass offset of either 143 or $146 \mathrm{u}$. An expanded portion of a constant neutral loss spectrum $(146 \mathrm{u})$ from the xenobiotic-treated bile extract that was methylated in this manner is presented in Figure $3 \mathrm{a}$. The xenobiotic-related twin ions were detected as a quartet at $m / z 448,449,451$, and 452 under these conditions, corresponding to the $\left[{ }^{13} \mathrm{C}_{0},{ }^{2} \mathrm{H}_{3}\right],\left[{ }^{13} \mathrm{C}_{1}\right.$, $\left.{ }^{2} \mathrm{H}_{3}\right],\left[{ }^{13} \mathrm{C}_{0},{ }^{2} \mathrm{H}_{6}\right]$, and $\left[{ }^{13} \mathrm{C}_{1},{ }^{2} \mathrm{H}_{6}\right]$ forms of the derivatized conjugates. The apparent distortion in the relative intensity of the $\mathrm{m} / \mathrm{z} 448$ ion was due to a contributing signal from the $m / z 445 / 448$ doublet, which was also present in the control bile (Figure $3 b$ ).

Structural information was generated through scanning the first-generation product ions formed from the protonated and sodium cationized forms of the candidate conjugate species with the native and derivatized crude bile extracts. Low-energy CAD (6 $\mathrm{eV})$ first-generation product ion spectra of the $\mathrm{m} / \mathrm{z}$ 417 and 418 (protonated) species are presented in Figures $4 \mathrm{a}$ and $4 \mathrm{~b}$. The single-letter nomenclature employed here for the proposed fragmentations (depicted in Figure 5) is the same as that employed previously [30] and subsequently adopted by others $[32,34]$. The molecular masses of the candidate species identified by the screening procedures suggested a conjugate structure that retained the pseudoaromatic character of the furan ring system without ring hydroxylation, and the first-generation product ion spectra were consistent with this hypothesis. Under lowenergy CAD conditions $(6-8 \mathrm{eV})$ the putative $e$ ions ( $m / z 288 / 289$ ), corresponding to the highly favored loss of the $\gamma$-glutamyl moiety, dominated the spectra and differed by $1 \mathrm{u}$ between the two spectra, as did other ions believed to contain the isotopic variants of 

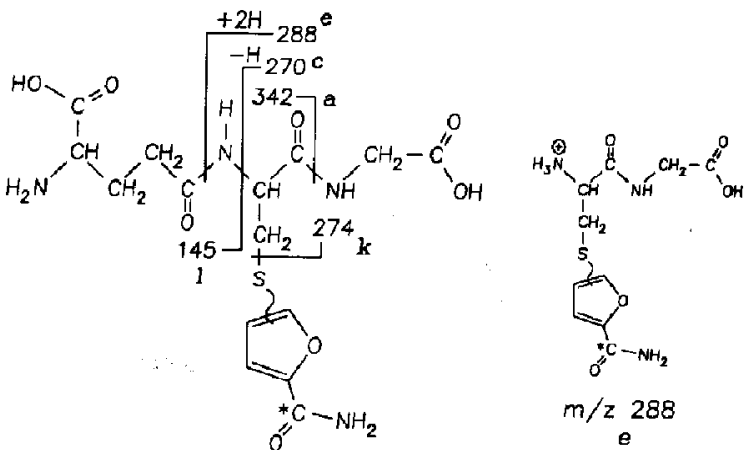

$\mathrm{m} / \mathrm{z} 288$

e
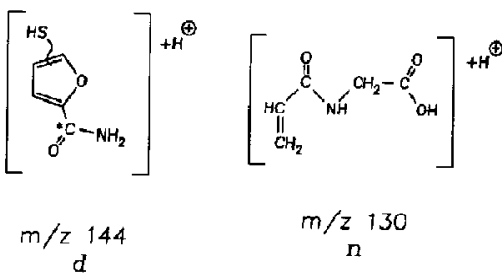

$\mathrm{m} / \mathrm{z} 185$

g

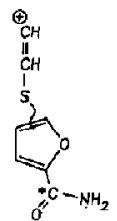

$\mathrm{m} / \mathrm{z} 168$

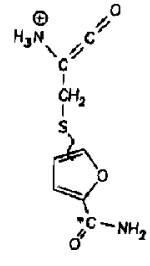

$m / z 213$

m<smiles>[CH]1C=CC1</smiles>

Figure 5. Proposed fragmentations of $m / z \quad 417$ and structures of the innic species observed in Figure 4. The asterisks indicate the location of the ${ }^{13} \mathrm{C}$ label The indicated $\mathrm{m} / \mathrm{z}$ values correspond to the unlabeled material. Fragmentation of the precursor structure is shown relative to the neutral molecule, without implication as to the site of initial protonation. the xenobiotic-derived side chain ( $a, c$, and $d$ ions). Conversely, the $m / z 274(k)$ ion, apparently derived through loss of the side-chain substituent, was present in both spectra. Other ions indicative of the nature of the side chain were generated at a somewhat higher collision energy $(70 \mathrm{eV})$, as depicted in Figures $4 \mathrm{c}$ and $4 \mathrm{~d}$, where the $d, g$, and $h$ ions were detected at higher relative abundance. Proposed structures for these ions are shown in Figure 5. The overall fragmentation pattern observed in these spectra is consistent with that observed previously for a variety of glutathione conjugates [30]. A similar fragmentation pattern was observed for the sodium cationized forms of the candidate (underivatized) species, with appropriate 22-u shifts observed for the fragment ions.

Complementary structural information is provided by the first-generation product ion spectra of the methylated material (Figures 6a and $6 \mathrm{~b}$ ). In these spectra, ions apparently incorporating the side-chain elements differ by $1 u$ between the two spectra, and appropriate 14-u shifts were observed between the ions of these spectra and those of the unmethylated material (Figure 4). The $e$ ions are again dominant in these low-energy (6 eV) CAD spectra, thus forming the basis of the alternative screening strategy discussed above that employed constant neutral loss scanning with a mass offset of $143 \mathrm{u}$. Interestingly, the first-generation product ion spectra of the sodium adducts of the methylated candidate species are both dominated by a single product ion of $m / z$ 324, as depicted in the expanded spectral regions shown in
Figure $7 \mathrm{a}$ and $7 \mathrm{~b}$. This observation was attributed to a sodium-induced alteration in the relative predominance of competing fragmentation pathways, such that loss of the side chain is the predominant pathway for the sodium cationized, methylated species (giving rise to the sodium cationized, bismethylated analogue of the $m / z 274(k)$ ion observed with the native material in Figures $4 a$ and $4 b$ ), as opposed to the predominance of the loss of the $\gamma$-glutamyl moiety ( $e$ ion) with the protonated species. Whereas these ions were isobaric for the unlabeled material, the relative contributions from the two alternative fragmentation pathways were well visualized with the ${ }^{1.3} \mathrm{C}$-labeled material (Figure $7 \mathrm{~b}$ ). The observation of an intense ion common to both spectra in Figure 7 suggested the possibility of employing precursor ion scanning as another alternative screening procedure. A precursor ion scan of the methylated xenobiotic-treated bile extract, with the tandem hybrid instrument set to scan for precursors of $m / z$ 324, is presented in Figure 8. Reduced and oxidized glutathione were again detected, and the candidate 2-furamide conjugates appeared as a doublet at $m / z 467 / 468$. The distortion of the relative intensities of these ions from a 1:1 doublet was attributed to the contribution from the isobaric $e$ ion from the $\mathrm{m} / \mathrm{z} 467$ material. It should be noted that no supplemental sodium was added to the sample or matrix in obtaining the spectra of Figures 7 and 8; the trace amounts of the ubiquitous sodium contaminant present in these "desalted" samples was sufficient to permit the acquisition of these scans.

Further structural information for the candidate 

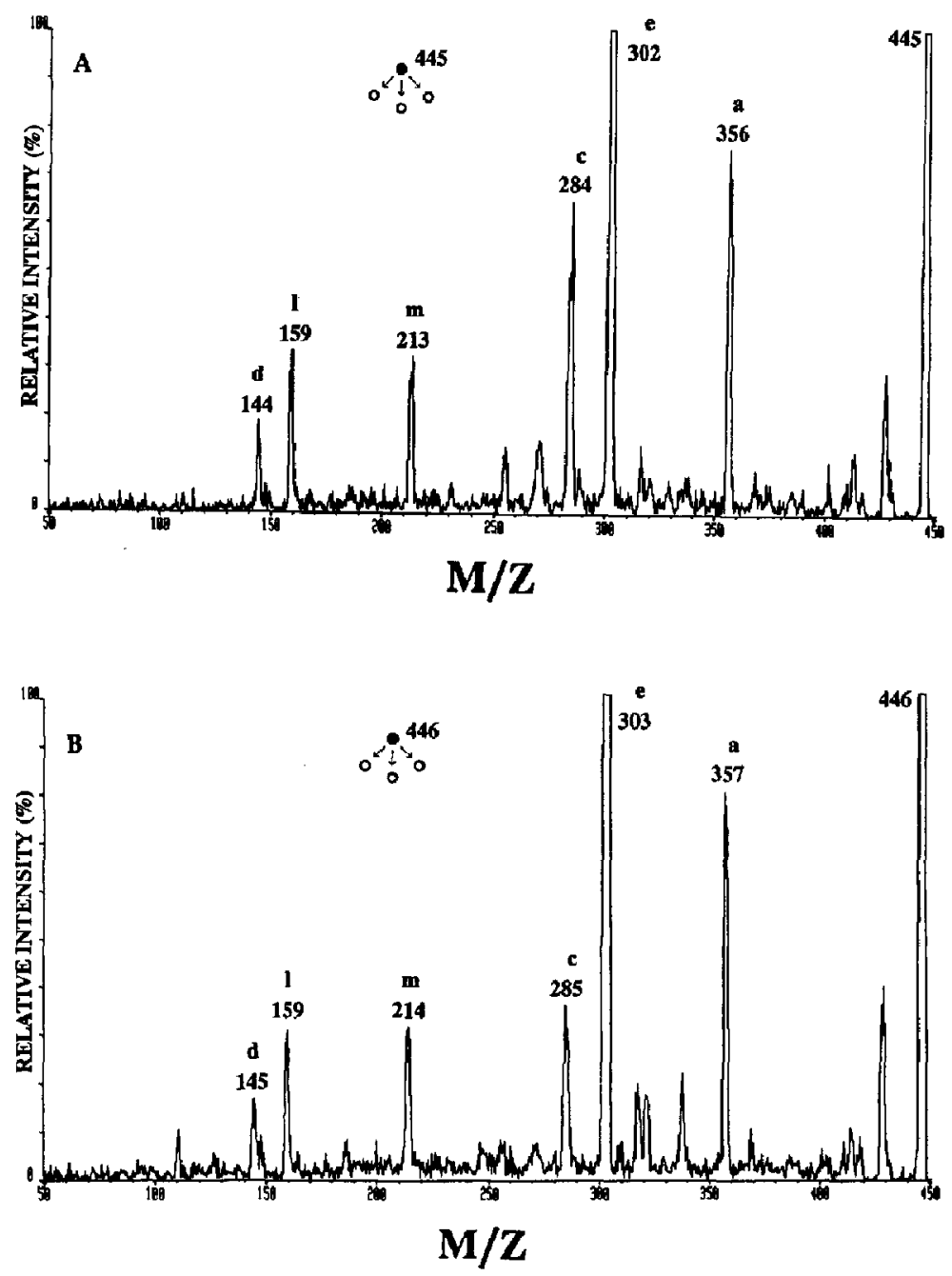

Figure 6. Low-energy CAD (6eV) first-generation product ion spectra of (a) $m / z 445$ and (b) $m / z 446$ species from the methylated xenobiotic-treated bile extract.

conjugate species was generated through second-generation product ion scanning (MS/MS/MS) using either of two approaches possible will the $\mathrm{BEC} Q \mathrm{Q}$ tandem hybrid instrument. In the first approach, sourceformed precursor ions selected with the magnet $(\mathrm{m} / \mathrm{z}$ 417 or 418 ) were allowed to decompose through metastable decay in FFR2 to yield the first-generation product ions. The ions corresponding to the loss of the $\gamma$-glutamyl moiety $(\mathrm{m} / \mathrm{z} 288$ or 289 ) were then selected with the electric sector and subjected to collisional activation $(70 \mathrm{eV})$ in the rf-only quadrupole. The second-generation product ions thus formed were analyzed by the quadrupole mass filter. The resulting second-generation product ion spectra from the xenobiotic-treated bile extracts are presented in Figure 9. These spectra clearly demonstrate that the putative $d$, $g$, and $h$ ions were derived from the putative $e$ ions, with appropriate 1-u shifts between the isotopic variants. The $m / z 130$ ion (which is also observed in
Figure 4) is common to the two spectra. In the absence of the MS/MS/MS data, the origin of the $m / z$ 130 ion is ambiguous; however, the observation that this ion was formed as a second-generation product from the $e$ ion, together with its lack of incorporation of the xenobiotic-derived side chain, permits the plausible attribution of this ion to the structure shown in Figure 5.

The above approach to MS/MS/MS has the advantages of good resolution of the precursor and secondgeneration product ions, but poor (ca. 300) effective resolution of the first-generation products. In an alternative approach, first-generation product ions formed in FFR1 rather than FFR2 are introduced into the rf-only quadrupole under CAD conditions, with subsequent mass analysis of the resulting second-generation products. This approach gives good resolution of the first- and second-generation product ions but poor effective resolution of the source-formed precursors 
Figure 7. Expanded regions of the furst-generation product ion spectra of (a) $m / z 467$ and (b) $m / z 468$ species from the methylated bile extracts, corresponding to the sodium adducts of the methylated glutathione conjugates of unlabeled and ${ }^{13} \mathrm{C}_{1}$-labeled 2-furamide.
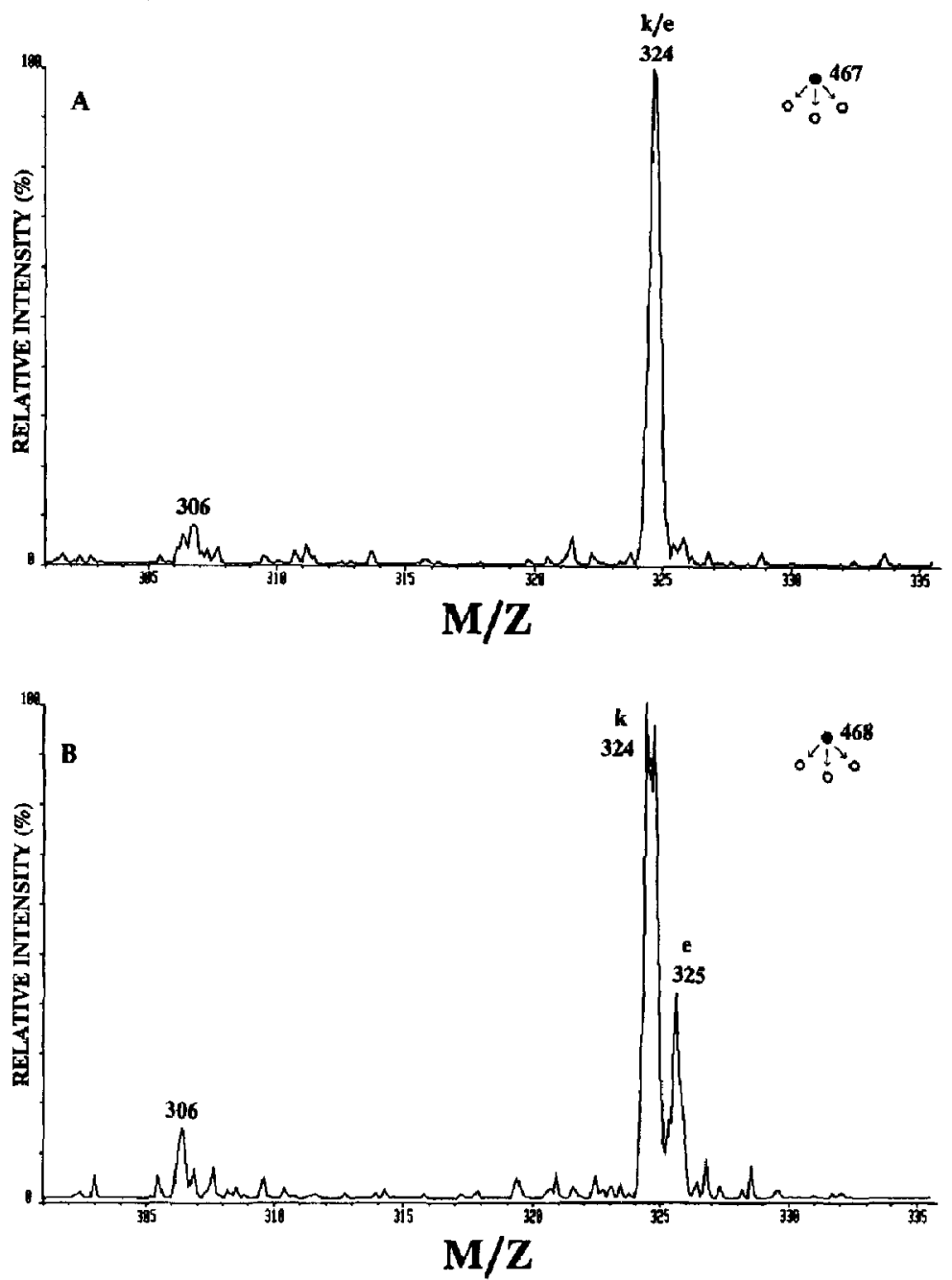

[52]. Analysis of the xenobiotic-treated bile extract by this approach yielded spectra virtually identical to those of Figure 9, with the exception of the presence of a contaminating ion of $m / z$ 137, which was demonstrated to be derived from the FAB matrix. Thus, even with the high structural specificity of MS/MS/MS techniques, the possibility of contributing signals from the background must be considered.

A summary of the ionic species observed from the candidate glutathione conjugates is presented in Figure 10. These data form a body of internally consistent evidence supporting the identification of the glutathione conjugate of 2-furamide, with the xenobiotic-derived portion of the conjugate retaining the pseudoaromatic furan ring system without ring hydroxylation. These data do not permit the identification of the location of substitution of the furan ring; high-energy CAD $(8 \mathrm{keV})$, using the mass-resolved ion kinetic energy scanning (MIKES) approach, yielded fragmentation patterns similar to those ob- served with low-energy CAD and was therefore also uninformative in this regard. This issue is the subject of continuing study.

The various scan modes employed in these studies, with their relative attributes and utilities, are tabulated in Table 1. Numerous other scan modes not pertinent to the present study are also accessible on this hybrid instrument. The unique versatility of this instrumental design makes it directly applicable to a wide variety of problems.

\section{Conclusions}

Application of a range of MS/MS techniques in the present study has resulted in the characterization of the glutathione conjugate resulting from the metabolism of 2-furamide as retaining the pseudoaromatic furan ring without ring hydroxylation. Further investigations are required to establish the site(s) of 

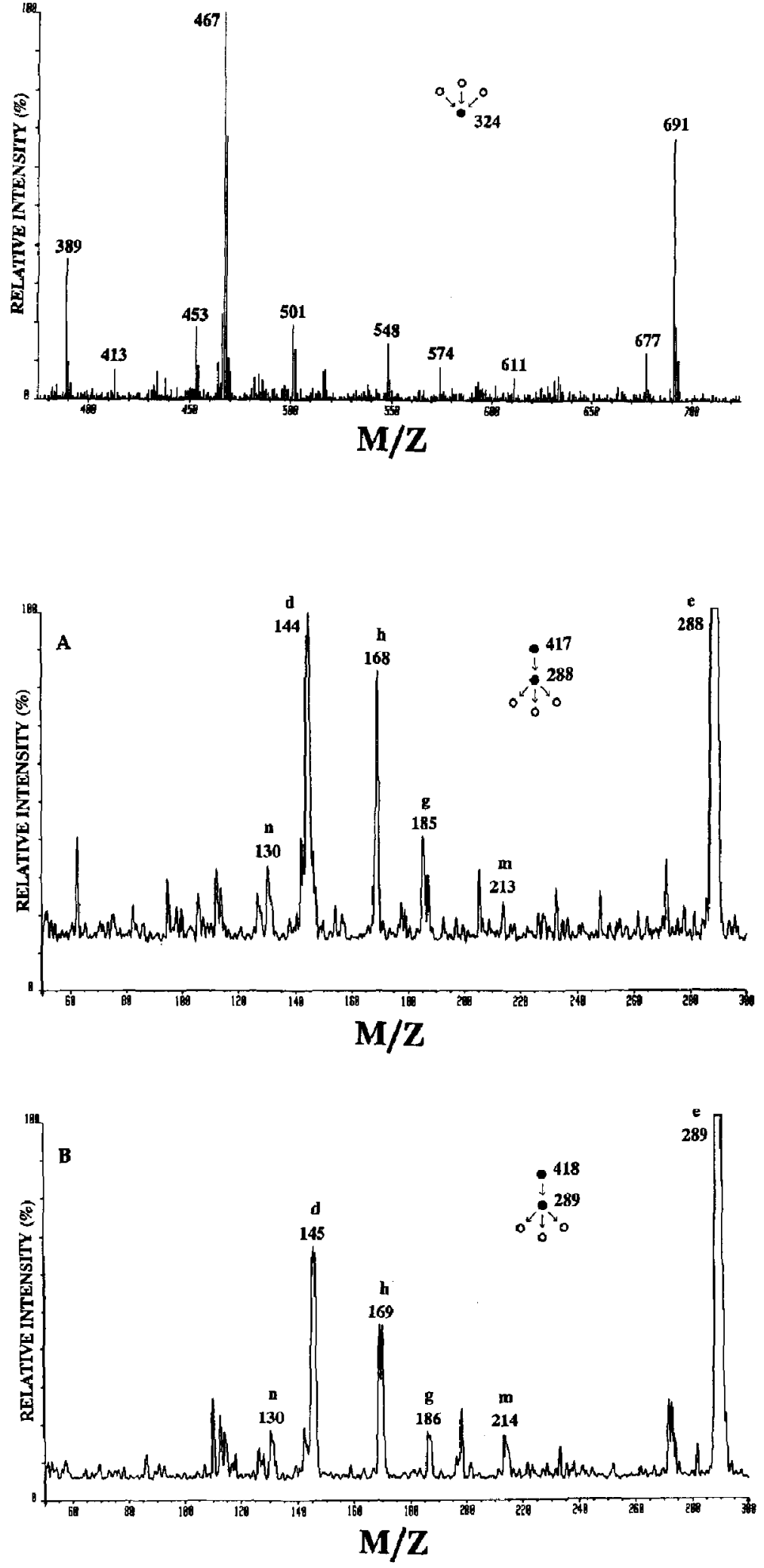

Figure 8. Precursor ion scan of the methylated xenobiotic-treated bile extract, monitoring precursors of $m / z 324$.
Figure 9. Second-generation product ion spectra (MS/MS/MS) from the xenobiotic-treated bile extract. (a) Secondgeneration CAD products of $m / z 288$ derived from metastable decay of $\mathrm{m} / \mathrm{z}$ 417 ; (b) second-generation CAD products of $m / z 289$ derived from metastable decay of $m / z 418$. 
Figure 10. Summary of the ionic species observed from the protonated and sodium cationized forms of the candidate glutathione conjugates from the native (unmodified) and derivatized xenobiotic-treated crude bile extracts.

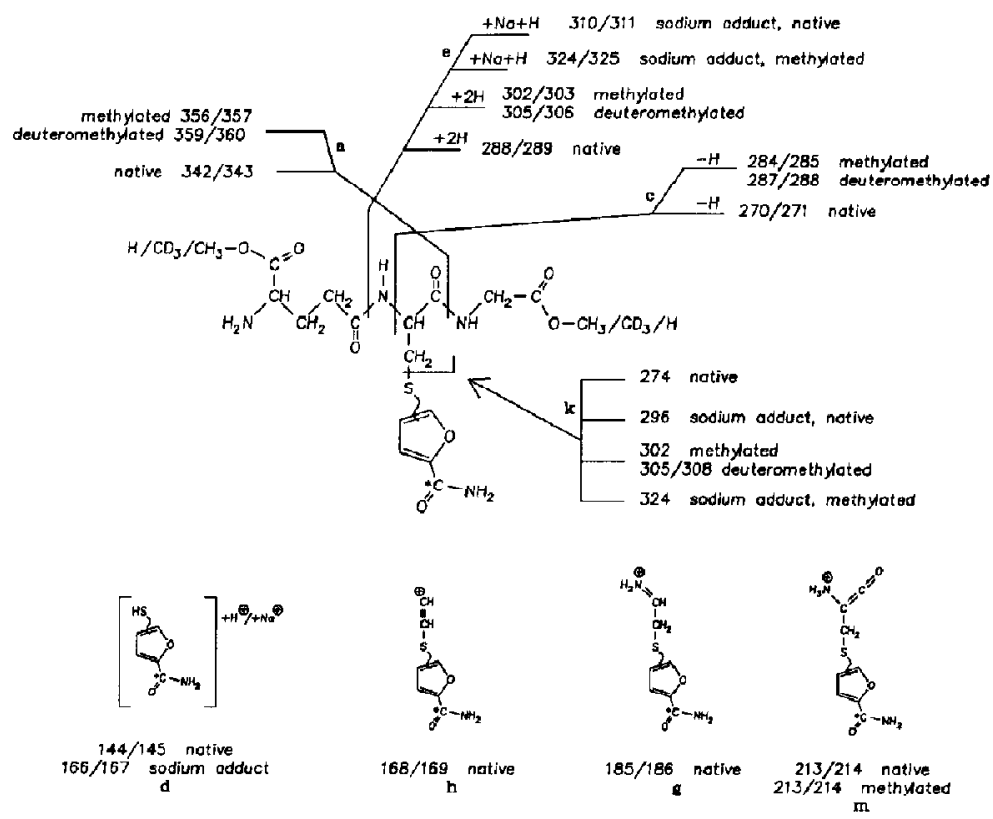

substitution of the furan ring. Previous metabolic studies of 2-furamide suggested activation by mixedfunction oxidases [53]. Although the mechanism of formation of the glutathione conjugate remains speculative, a plausible route involves initial epoxidation followed by nucleophilic substitution by glutathione and subsequent dehydration to restore the pseudoaromatic structure.

The twin ion technique has repeatedly been shown to facilitate drug metabolism studies. The use of compound class selective screening procedures, such as constant neutral loss or precursor ion scanning, in conjunction with this technique can further facilitate the rapid identification of candidate xenobiotic metabolites that may not be readily discernible in the conventional FAB spectra of complex biological mixtures. The hybrid tandem mass spectrometer is particularly well suited for complex mixture analysis. The

Table 1. Scan modes used in the screening and characterization of glutathione conjugates

\begin{tabular}{|c|c|c|c|c|c|c|}
\hline \multirow[b]{2}{*}{ Scan mode } & \multicolumn{2}{|c|}{ Acquisition } & \multirow{2}{*}{$\begin{array}{l}\text { Decompo- } \\
\text { sition } \\
\text { region }\end{array}$} & \multirow{2}{*}{$\begin{array}{l}\text { Collision } \\
\text { energy }\end{array}$} & \multirow{2}{*}{$\begin{array}{l}\text { Effective } \\
\text { mass } \\
\text { resolution }\end{array}$} & \multirow[b]{2}{*}{ Application } \\
\hline & Static & Scanned & & & & \\
\hline $\begin{array}{l}\text { 1st-generation } \\
\text { product ion } \\
\text { scan }\end{array}$ & $B$ and $E$ & 0 & $\mathrm{q}$ & $8-70 \mathrm{eV}$ & $\begin{array}{l}>1000 \text { (precursor): } \\
\text { unit (1st gen. products) }\end{array}$ & $\begin{array}{l}\text { Structural } \\
\text { information }\end{array}$ \\
\hline $\begin{array}{l}\text { constant } \\
\text { noutral loss } \\
\text { scan }\end{array}$ & E & $B$ and $Q$ & $q$ & $8 \mathrm{eV}$ & $\begin{array}{l}>1000 \text { (precursor); } \\
\text { unit (1st gen. products) }\end{array}$ & $\begin{array}{l}\text { Compound } \\
\text { class screening }\end{array}$ \\
\hline $\begin{array}{l}\text { precursor ion } \\
\text { scan }\end{array}$ & $\mathrm{Q}$ and $\mathrm{E}$ & B & $q$ & $22 \mathrm{eV}$ & $\begin{array}{l}>1000 \text { (precursor); } \\
\text { unit (1st gen. products) }\end{array}$ & $\begin{array}{l}\text { Compound } \\
\text { class screening }\end{array}$ \\
\hline $\begin{array}{l}\text { 2nd-generation } \\
\text { product ion } \\
\text { scan (mode } 1 \text { ) }\end{array}$ & $B$ and $E$ & 0 & $\begin{array}{l}\text { FFR2 (1) } \\
q(2)\end{array}$ & $\begin{array}{l}\text { Metastable }\{1\} \\
70 \mathrm{eV}(2)\end{array}$ & $\begin{array}{l}>1000 \text { (precursor); } \\
\text { ca. } 300 \text { (1st gen. products); } \\
\text { unit ( } 2 \text { nd-gen. products) }\end{array}$ & $\begin{array}{l}\text { Highly } \\
\text { specific } \\
\text { structural } \\
\text { information }\end{array}$ \\
\hline $\begin{array}{l}\text { 2nd-generation } \\
\text { product ion } \\
\text { scan (mode 2) }\end{array}$ & $B$ and $E$ & Q & $\begin{array}{l}\text { FFF 1 (1) } \\
q(2)\end{array}$ & $\begin{array}{l}\text { Metastable " (1) } \\
70 \mathrm{eV}(2)\end{array}$ & $\begin{array}{l}\text { Ca. } 300 \text { (precursor); } \\
\text { ca. } 800 \text { (1st-gen. products); } \\
\text { unit (2nd-gen. products) }\end{array}$ & $\begin{array}{l}\text { Highly } \\
\text { specific } \\
\text { structural } \\
\text { information }\end{array}$ \\
\hline
\end{tabular}

'Whereas these decompositions are nominally designated as metastable, the potential exists for a significant contribution from $C A D$ because of the presence of the $F A B$ gas escaping from the ion source region. 
multiple scan modes that are readily accessible on hybrid sector/quadrupole instruments, together with facile control of collision energy regimes and the availability of multiple approaches to MS/MS/MS, facilitate the generation of readily interpretable screening and structural data even in the presence of comparatively high chemical background. Furthermore, the individual experiments described here were relatively brief; in the application of these techniques to other unknown glutathione conjugates, the entire complement of mass spectrometric analyses described here could be performed during two working days. Simple derivatization strategies can supplement the various MS/MS approaches to facilitate thorough characterization of individual species within biological mixtures without the need for overly complicated purification scliemes.

\section{Acknowledgments}

The VG ZAB SEQ mass spectrometer was purchased by the Howard Hughes Medical Institute. This work was supported in part by the National Institutes of Health (GM 34120 and AI 26916). Additional support was generously provided by the Burroughs Wellcome Company.

\section{References}

1. Mitchell, J. R.; Jollow, D. J.; Potter, W. Z.; Davis, D. C.; Gillette, J. R.; Brodie, B. B. J. Phamacol. Exp. Ther. 1973, 187, 185-194.

2. Jollow, D. J.; Mitchell, J. R.; Potter, W. Z.; Davis, D. C.; Gillette, J. R.; Brodie, B. B. J. Pharnacol. Exp. Ther. 1973, 187, 195-202.

3. Potter, W. Z;; Davis, D. C.; Mitchell, J. R.; Jollow, D. J.; Gillette, J. R.; Brodie, B. B. J. Pharmacol. Exp. Ther. 1973, $187,203-210$.

4. Mitchell, J. R.; Jollow, D. J.; Potter, W. Z.; Gillette, J. R.; Brodie, B. B. I. Pharmacol. Exp. Ther. 1973, 187, 211-217.

5. Mitchell, J. R. Personal communication, 1987.

6. Lamoreux, G. L.; Rusness, D. G. J. Agric. Food Chem. 1980, 28, 1057-1070.

7. Nelson, S. D.; Mitchell, J. R.; Pohl, L. R. In Mass Spectrometry in Drug Metabolism; Frigerio, A.; Ghisalberti, E., Eds.; Plenum: New York, 1977; pp 237-249.

8. Meerman, J. H. N.; Beland, F. A.; Ketterer, B.; Srai, S. K.; Bruins, A. P.; Mulder, G. J. Chem. Biol. Interact. 1982, 39, $149-168$.

9. Hughes, H.; Lauterburg, B. H.; Horning, M. G.; Carrol, D. I.; Horning, E. C.; Mitchell, J. R. Pharntacologist 1982. 24, 147.

10. Nelson, S. D.; Vaishnav, Y.; Kambara, H.; Baillie, T. A. Biomed. Mass Spectrom. 1981, 8, 244-251.

11. Tunek, A.; Platt, K. I.; Pryzhylski, M.; Oesch, F. Chem. Biol. Interact. 1980, 33, 1-17.

12. Pryzbylski, M,; Cysyk, R. L.; Shoemaker, D.; Adamson, R. H. Biomed. Mass Spectrom. 1981, 8, 485-491.

13. Moss, E. J.; Judah, D. J.; Pryzbylski, M.; Neal, G. E. Biochem. J. 1983, 210, 227-233.

14. Gaudich, K.; Pryzbylski, M. Biomed. Mass Spectrom. 1983, 10, 292-299.

15. Mulder, G. H.; Unruh, L. E.; Evans, F. E.; Ketterer, B.; Kadlubar, F. F. Chem. Biol. Interact. 1982, 39, 111-127.
16. Ackermann, B. L.; Watson, J. T,; Newton, J. F.; Hook, J. B.; Braselton, W. E. Biomed. Mass Spectrom. 1984, 11, 502-511.

17. Correia, M. A.; Krowech, G.; Caldera-Munoz, P.; Yee, S. L.; Straub, K.; Castagnoli, N. Chem. Biol. Interact. 1984, 51, 13-24.

18. Hutson, D. H.; Lakeman, S. K.; Logan, C. J. Xenobiotica 1984, 14, 925-934.

19. Ross, D.; Larsson, R.; Norbeck, K.; Ryhage, R.; Moldeus, P. Mol. Pharmacol. 1985, 27, 277-286.

20. Spearman, M. E.; Prough, R. A.; Estabrook, R, W,; Falck, J. R.; Manna, S.; Leibman, K. C.; Murphy, R. C.; Capdevila, J. Arch. Biochem. Biophys. 1985, 242, 225-230.

21. Pallante, S. L.; Lisek, C. A.; Dulick, D. M.; Fenselau, C. Drug Metab. Dispos. 1986, 14, 313-318.

22. Dulick, D. M.; Fenselau, C.; Hilton, ]. Biochem. Pharmacol. 1986, 35, 3405-3409.

23. Baillie, T. A,; Hoffman, K.-J.; Axworthy, D. B. In Advances in Mass Spectrometry 1985, Part B; Todd, J. F. J., Ed.; Wiley: Chichester, 1986; pp 1267-1268.

24. Straub, K. M. In Mass Spectrometry in Biomedical Research; Gaskell, S. J., Ed.; Wiley: Chichester, 1986; pp 115-134.

25. Stock, B. H.; Bend, J. R.; Eling, T. E. J. Biol. Chem. 1986, 261, 5959-5964.

26. Stock, B. H.; Schrieber, J.; Guenat, C.; Mason, R. P.; Bend, J. R.; Eling, T, E. J. Biol. Chem. 1986, 261, 15915-15922.

27. Foureman, G. L.; Reed, D. J.; Biochemistry 1987, 26 , 2028-2033.

28. Lay, J. O.; Potter, D. W,; Hinson, J. A. Biomed. Environ. Mass Spectrom. 1987, 14, 517-521.

29. Threadgill, M. D.; Axworthy, D. B.; Baillie, T. A.; Farmer, P. B.; Farrow, K. C.; Gescher, A.; Kestell, P.; Pearson, P. G.; Shaw, A. J. J. Pharmacol. Exp. Ther, 1987, 242, 312-319.

30. Haroldson, P. E.; Reilly, M. H.; Hughes, H.; Gaskell, S. J.; Porter, C. J. Biomed. Environ. Mass Spectrom, 1988, 15, 615-621.

31. I Ioffman, K.-I.; Baillie, T. A. Biomed. Environ. Mass Spectrom. 1988, 15, 637-647.

32. Pearson, P. G.; Threadgill, M. D.; Howald, W. N.; Baillie, T. A. Biomed. Environ. Mass Spectrom. 1988, 16, 51-56.

33. Tomer, K. B.; Guenat, C.; Dino, J. J.; Deterding, L. J. Biomed. Environ. Mass Spectrom. 1988, 16, 473-476.

34. Pearson, P. G; Slater, J, G; Rashed, M. R.; Han, D.-H.; Grillo, M. P.; Baillie, T. A. Biochem. Biophys. Res. Commun. 1989, 166, 245-250.

35. Nocerini, M. R.; Yost, G. S.; Carlson, J. R.; Liberato, D. J.; Breeze, R. G. Drug Metab. Dispos. 1985, 13, 690-694.

36. Betowski, L. D.; Korfmacher, W. A.; Lay, J. O.; Potter, D. W.; Hinson, J. A. Biomed. Environ. Mass Spectrom. 1987, 14, $705-709$.

37. Sesame, H. A.; Liberto, D. J.; Gillette, J. R. Drug Metab. Dispos. 1987, 15, 349-355.

38. Parker, C. E.; de Wit, J. S. M.; Smith, R. W.; Gopinathan, M. B.; Hernandez, O.; Tomer, K. B.; Vestel, C. H.; Sanders, J. M.; Bend, I. R. Biomed. Environ. Mass Spectrom. 1988, 15, 623-634.

39. Rashed, M. R.; Pearson, P. G.; Han, D.-H.; Baillie, T. A. Rapid Commun. Mass Spectrom. 1989, 10, 360-363.

40. Bean, M. F.; Pallante-Morell, S. L.; Dulik, D. M.; Fenselau, C. Anal. Chem. 1990, 62, 121-124.

41. Dulik, D. M.; Colvin, O. M.; Fenselau, C. Biomed. Environ. Mass Spectrom. 1990, 19, 248-252.

42. Pearson, P. G.: Howald W. N.; Nelson, 5. D.; Bailie, T. A Proceedings of the 37th ASMS Conference on Mass Spectrometry and Allied Topics; Miami Beach, May 21-26, 1989; $\mathrm{p} 1322$.

43. Ramanathan, V.; Levine, R. J- Org. Chem. 1962, 27, 1216-1219.

44. Baum, E, Chem, Ber, 1904, 37, 2949-2961.

45. Sonntag, N. O. V. Chem. Rev, 1953, 52, 237-416. 
46. Schaaper, W. M. M.; Voskamp, D.; Olieman, C. I. Chromatogr. 1980, 195, 181-186.

47. Brown, C. A.; Bennett, H. P. J.; Solomon S. In High Performance Liquid Chromatography of Proteins and Peptides; Hearn, M. T. W.; Regnier, F. E.; Wehr, C. T., Eds.; Academic: New York, 1983; PP 65-72.

48. Thorne, G. C.; Gaskell, S. J. Rapid Commun. Mass Spectrom. 1989, 3, 217-221.

49. Braselton, W. E.; Orr, J. C.; Engel, L. L. Anal. Biochem.
1973, 53, 64-85.

50. Garland, W. A.; Powell, M. A. I. Chromatogr. Sci. 1981, 19, 392-343.

51. Louris, J. N.; Wright, L. G.; Cooks, R. G.; Schoen, A. E. Anal. Chem. 1985, 57, 2918-2924.

52. Jennings, K. R.; Mason, R. S. In Tandem Mass Spectrometry; Mclafferty, F. W., Ed.; Wiley: New York, 1983; pp 197-222.

53. McMurty, R. J.; Mitchell, J. R. Toxicol. Appl. Pharmacol. 1977, $42,285-300$. 